\title{
Soot Combustion Activity and Potassium Mobility in Diesel Particulate Filters Coated with a K-Ca-Si-O Glass Catalyst
}

James Zokoe, ${ }^{a}$ Changsheng Su, ${ }^{a}$ Paul J McGinn ${ }^{b^{*}}$

${ }^{a}$ Cummins Inc., 1900 McKinley Ave., Columbus, IN 47201, USA

bDepartment of Chemical and Biomolecular Engineering

University of Notre Dame, Notre Dame, IN 46556; pmcginn@nd.edu 


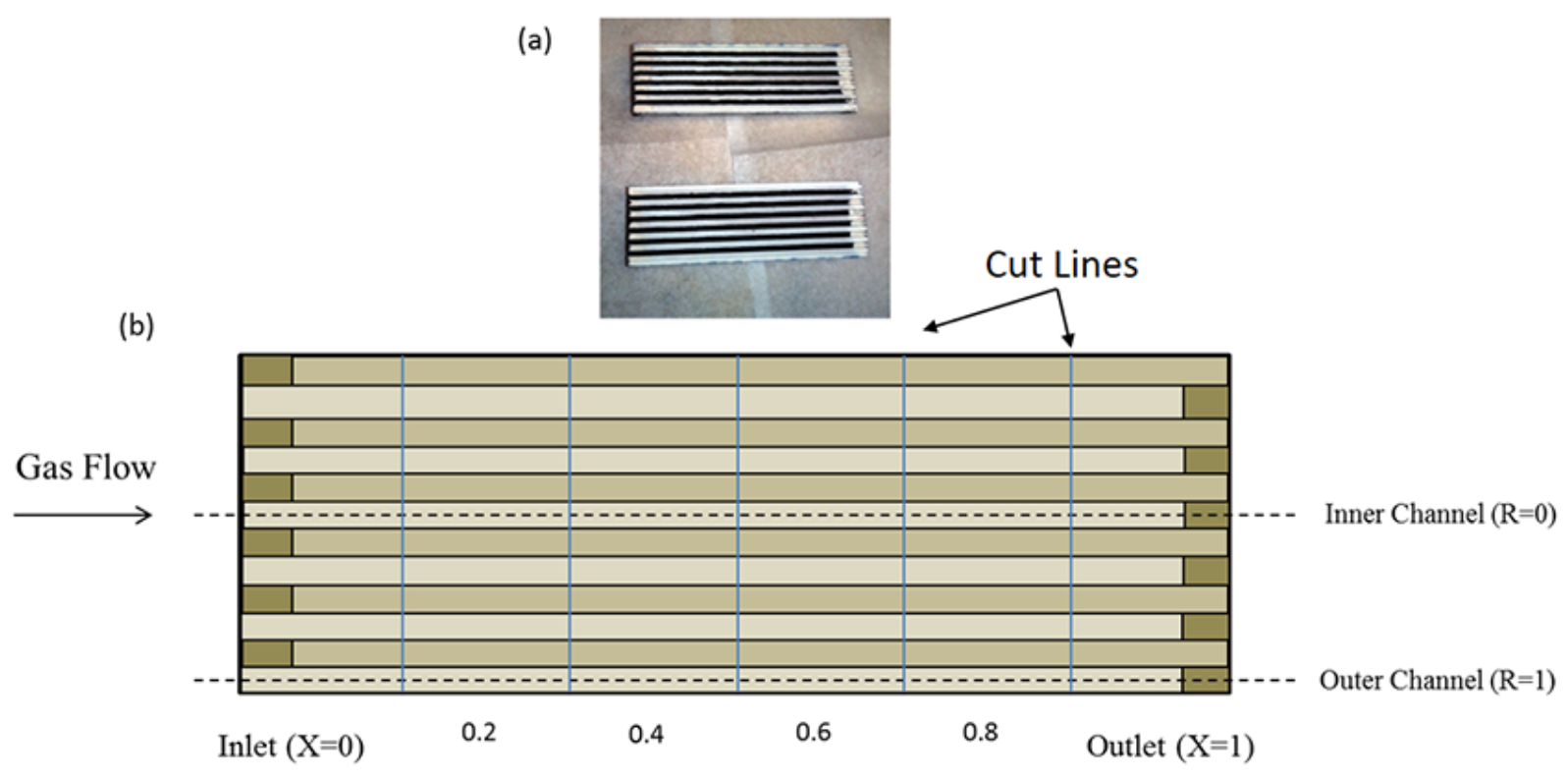

Figure S1 - Sample preparation methodology for the degradation characterization of the end of useful life (EUL) tested 1 x 3" K-Mullite filter core. (a) example of cleaved filter core (b) schematic of sample cutting and determination of coordinates. 


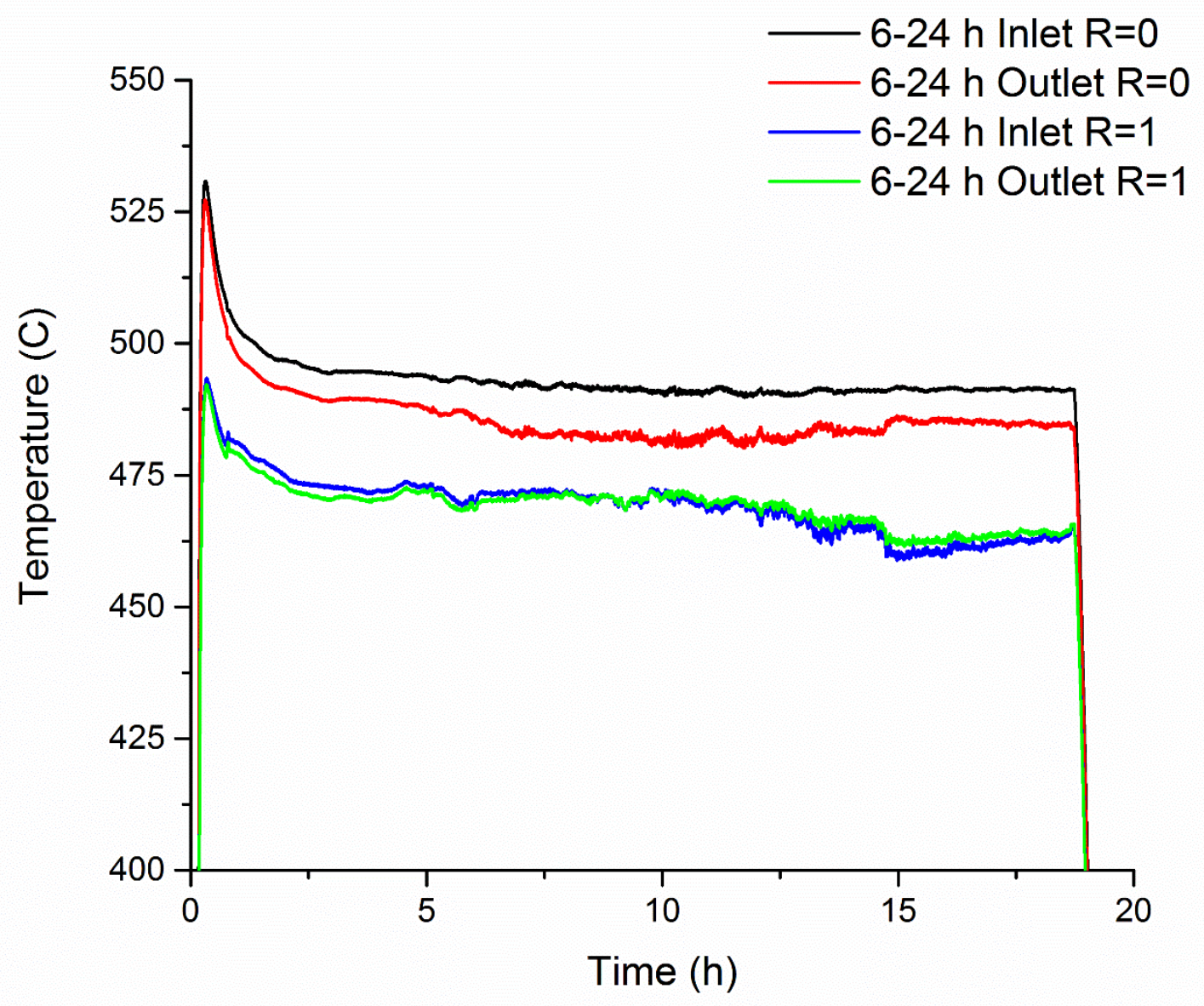

Figure S2 - Axial and radial temperature profiles in a downstream bare mullite core used for capturing volatilized $\mathrm{K}$. 


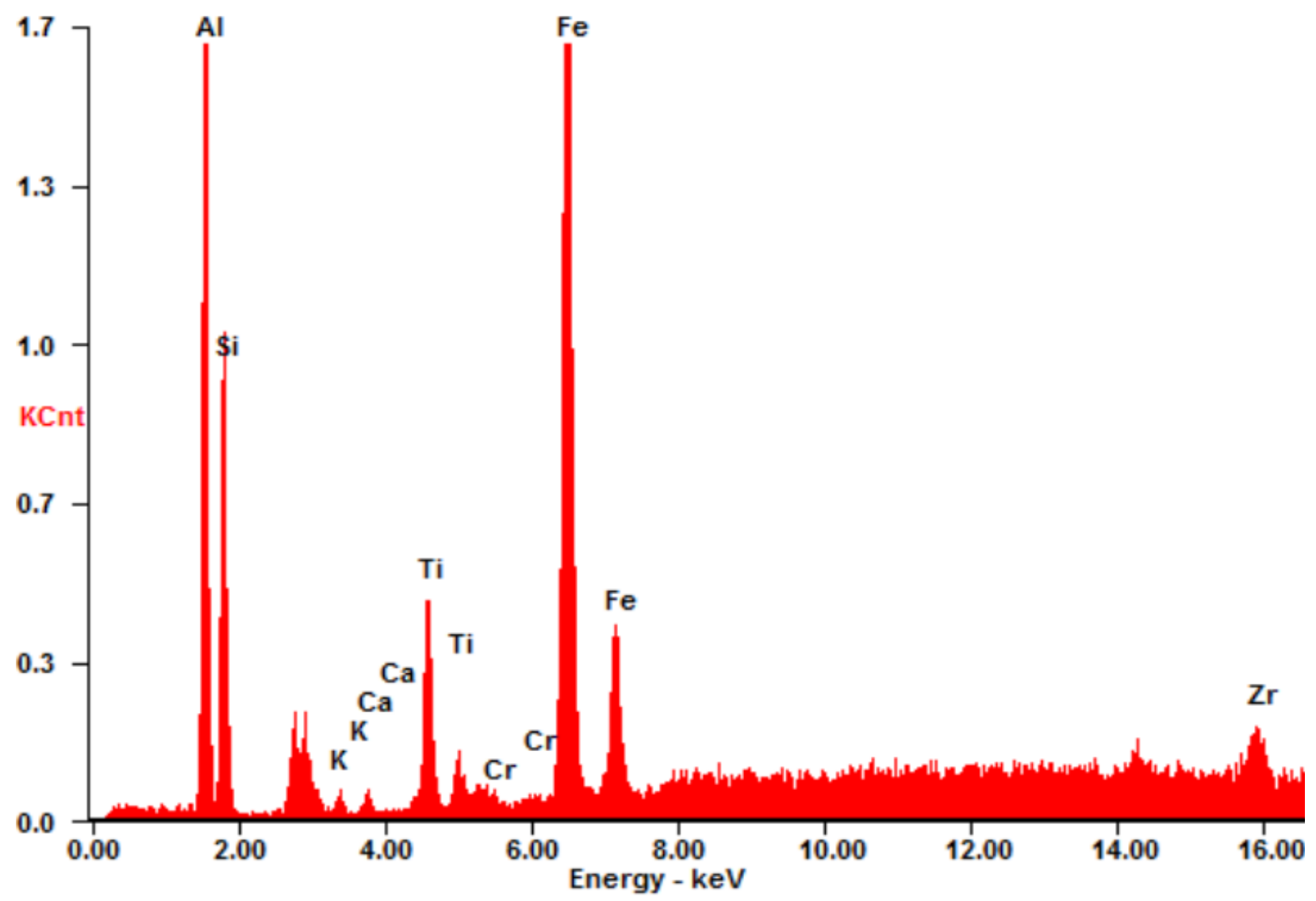

Figure S3 - XRF spectrum of downstream mullite core after the $24-50 \mathrm{~h}$ soot oxidation segment. 
(a)

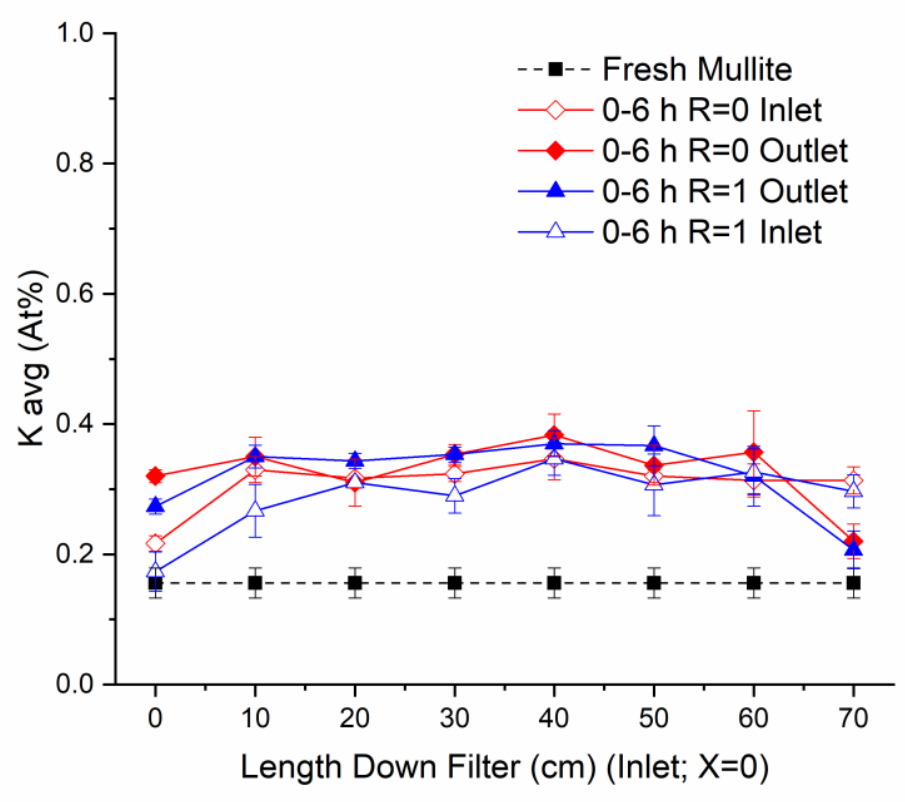

(b)

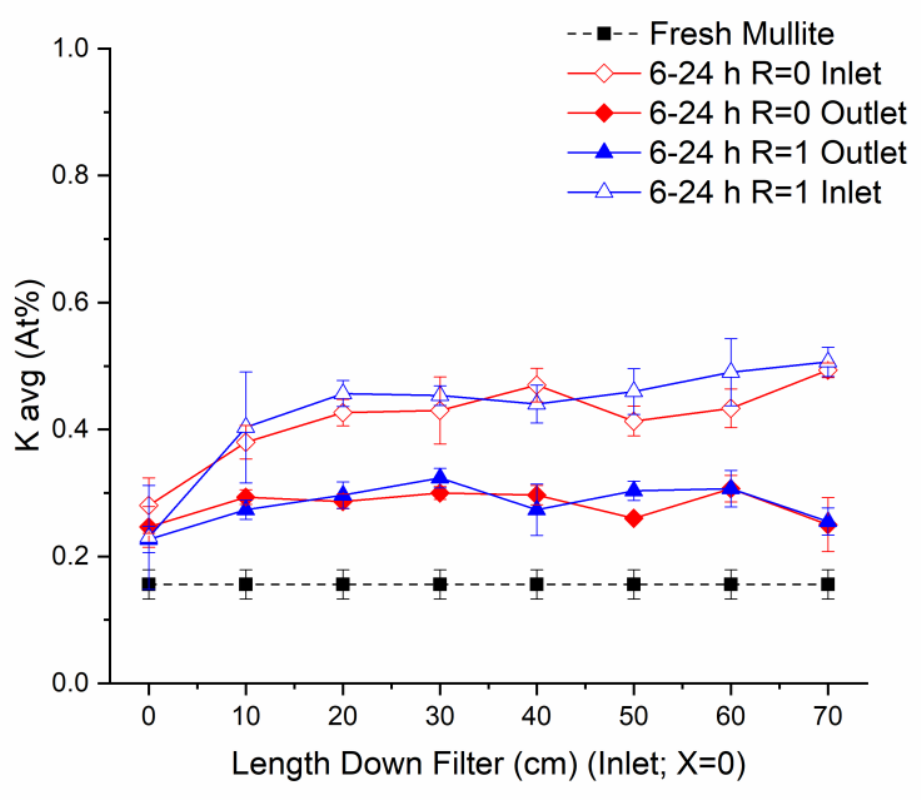

Figure S4 XRF measured K content (At\%) down the axial length of the downstream uncoated mullite filters for $\mathrm{R}=0, \mathrm{R}=1$ inlet and outlet channels (axial and radial distribution). Measurements are of the separate mullite cores (a) 0-6 h, (b) 6-24 h, of continuous soot oxidation. 


\section{Supplementary Table 1}

Spherical precipitates of the type shown in Figure 6 were analyzed at 5 different locations

\begin{tabular}{|llllll|}
\hline \multicolumn{5}{c|}{ Element (at \%) } \\
\hline Ppt. & O & Al & Si & K & Total \\
\hline 1 & 55.69 & 0.97 & 32.61 & 10.73 & 100.00 \\
\hline 2 & 60.20 & & 29.93 & 9.87 & 100.00 \\
\hline 3 & 58.54 & 31.59 & 9.87 & 100.00 \\
\hline 4 & 60.12 & 29.70 & 10.18 & 100.00 \\
\hline 5 & 62.13 & 29.06 & 8.80 & 100.00 \\
\hline
\end{tabular}

